Revista Ceuma Perspectivas, Edição Especial. VII Congresso de Inovação, Tecnologia e Sustentabilidade Ceuma.

Vol. 34, nº2, 2019.

ISSN Eletrônico: 2525-5576.

\title{
INOVAÇÃO TECNOLÓGICA NA INDÚSTRIA DA CONSTRUÇÃO CIVIL: USO DO SEIF COMO MONITORAMENTO E GESTÃO DE SEGURANÇA NO TRABALHO
}

\section{TECHNOLOGICAL INNOVATION IN THE CONSTRUCTION INDUSTRY: THE USE OF SEIF AS A MONITORING OF THE OCCUPATIONAL SECURITY MANAGEMENT}

\begin{abstract}
Antonia Keely Araujo da Silva ${ }^{1}$, Emilly Silva Castelo Branco ${ }^{2}$, Kellen Fernanda da Silva Rego ${ }^{3}$, Flávio Henrique de Jesus Pestana Sousa ${ }^{4}$
\end{abstract}

RESUMO: Devido ao atual cenário da indústria da construção civil nasce a necessidade de programas que aperfeiçoem os métodos de planejamento e controle de segurança, o SEIF surgiu como proposta para promover um comportamento seguro no ambiente de produção ocasionando uma diminuição de acidentes e de custos com ações trabalhistas. Essa proposta visa o cumprimento das Normas Regulamentadoras vigentes de Segurança e Saúde no Trabalho (SST), possibilitando que os gestores, as equipes e responsáveis pela preservação da saúde acompanhem em tempo real a condição de segurança dos trabalhadores no canteiro de obra.

PALAVRAS-CHAVE: Segurança do trabalho. SEIF. Controle de segurança.

\begin{abstract}
Due to the current scenario of the construction industry, the need for programs that improve the methods of planning and controlling security is born. The SEIF came as a proposal to promote a safe behavior in the production environment leading to a reduction in accidents and in the costs of labor actions. This proposal aims to comply with the Occupational Safety and Health Regulatory Standards, making managers, teams and health preservers able to monitor in real time the condition of workers' safety at the construction area.
\end{abstract}

KEYWORDS: Work safety. SEIF Security control.

\footnotetext{
${ }^{1}$ Discente do curso de Eng. Civil, na Universidade Ceuma. E-mail: keelysilvaa@ hotmail.com 2 Discente do curso de Eng. Civil, na Universidade Ceuma. E-mail: emillycastelob@gmail.com 3 Discente do curso de Eng. Civil, na Universidade Ceuma. E-mail: el.kfernanda@gmail.com 4 Eng $^{\circ}$ Civil. Especialista em Segurança do Trabalho. Docente na Universidade Ceuma. E-mail: flavio.pestana@hotmail.com
} 
Revista Ceuma Perspectivas, Edição Especial. VII Congresso de Inovação, Tecnologia e Sustentabilidade Ceuma.

Vol. 34, nº2, 2019.

ISSN Eletrônico: 2525-5576.

\section{INTRODUÇÃO}

A diversidade em inovações tecnológicas tem ganhado cada vez mais espaço dentro das empresas, sendo elas de grande valia inclusive dentro da Construção Civil. Aspirando a melhoria de vida dos trabalhadores, desenvolvimentos tecnológicos têm sido eficientes quanto a Saúde e Segurança do Trabalho prevenindo acidentes e proporcionando soluções ousadas e inovadoras. Dentre esses desenvolvimentos está o SEIF (Segurança, Informação e Formação), que se refere a uma plataforma tecnológica de monitoramento que facilita de forma satisfatória o desempenho seguro no ambiente de trabalho, usando sensores embutidos em EPI (Equipamento de Proteção Individual), uniformes ou em acessórios vestíveis.

Progressivamente as empresas tem buscado se adaptar com o uso de tecnologia e ao modelo de indústria 4.0 - modelo que engloba inovações tecnológicas dos campos de automação, controle e tecnologia da informação usando Sistemas Cyber-Físicos, Internet das Coisas e Internet dos Serviços - devido a isso a relevância do SEIF como inovação se dá pela busca do progresso, visando a melhoria na gestão de segurança no trabalho, permitindo que gestores, equipes e responsáveis pela preservação da saúde acompanhem de forma instantânea a condição de segurança dos trabalhadores em campo e o cumprimento das Normas Regulamentadoras vigentes na de Segurança e Saúde no Trabalho (SST), evitando e reduzindo os custos gastos com a suspensão de funcionários devido a acidentes, multas e eventuais ações trabalhistas.

Essa plataforma tem como objetivo explorar novos métodos de gestão, através da modernização fornecendo ferramentas que permitam a digitalização dos processos de SST e permitem o monitoramento instantâneo das condições ambientas do trabalhador possibilitando a preparação e qualificação do trabalho de gestores para minimizar os riscos que os empregados estarão expostos naquele local, além da automatização de alertas de vencimentos de EPI, ASO (Atestado de Saúde Ocupacional), manutenção de máquinas, entre outros. 
Revista Ceuma Perspectivas, Edição Especial. VII Congresso de Inovação, Tecnologia e Sustentabilidade Ceuma.

Vol. 34, nº2, 2019.

ISSN Eletrônico: 2525-5576.

A ênfase do trabalho é a implementação desse projeto para maior eficiência no monitoramento e no gerenciamento das atividades realizadas no ambiente de produção evitando ao máximo condições insalubres.

\section{MATERIAL E MÉTODOS}

\subsection{Quanto aos fins}

Sabe-se que a Indústria de Construção Civil (ICC) possui alto índice de ações trabalhistas quando se trata de SST, pois os sistemas disponibilizados aos gestores de segurança não apresentam as aplicabilidades necessárias para gerenciar, acompanhar e mitigar acidentes, portando a finalidade dessa pesquisa após a identificação do problema é contrastar o âmbito trabalhista antes do uso do SEIF e após ele para avaliar os resultados.

\subsection{Quanto aos meios}

Para o desenvolvimento da pesquisa apresentada e a idealização dessa inovação inicialmente foi necessário um estudo comparativo com os produtos existentes, posteriormente avaliações laboratoriais, de campo e teste piloto em um estudo de caso para possibilitar a validação dessa solução.

\subsection{Quanto a abordagem}

A presente pesquisa foi qualitativa a medida que propiciou a apresentação de uma análise do processo atual de produção e sugerindo uma otimização no processo produtivo, buscando majoritariamente o desenvolvimento de maneira a introduzir mudanças rápidas e econômicas no âmbito empresarial

\subsection{Quanto a natureza}

O SEIF será aplicado com o intuito de executar melhorarias nos monitoramentos dos trabalhadores favorecendo na redução de acidentes nos canteiros de obra, e consequentemente no aperfeiçoamento estratégico do processo de gestão da empresa em busca de estar em conformidade com as legislações vigentes. 
Revista Ceuma Perspectivas, Edição Especial. VII Congresso de Inovação, Tecnologia e Sustentabilidade Ceuma.

Vol. 34, nº2, 2019.

ISSN Eletrônico: 2525-5576.

\section{RESULTADOS E DISCUSSÕES}

O Serviço Social da Indústria (SESI) é encarregado pela escolha de propostas empreendedoras registradas nas categorias Inovação em Saúde, Segurança do Trabalho, Promoção da Saúde e Inovação Setorial para Indústrias de Construção. O Centro de Inovações SESI desenvolveu o SEIF como uma dessas propostas, que inicialmente está sob teste na obra de um complexo residencial formado por duas torres de 81 andares cada uma , correspondente a 280 metros de altura que serão os maiores da América Latina, localizado em Balneário Camboriú (SC), em Santa Catarina pela construtora Pasqualotto \& GT.

Segundo o artigo publicado pelo SESI e premiado pela Câmara Brasileira da Indústria da Construção (CBIC), no SEIF são utilizados sensores embutidos em EPI, uniformes e acessórios de trabalhadores que mapeiam situações de risco no âmbito de expediente. Essas informações são enviadas direto aos gestores de segurança e saúde da empresa, que transpassam o sistema web e mobile que serão armazenadas e processadas em nuvem (cloud computing), garantindo segurabilidade, sincronização, celeridade e escalabilidade tecnológica, e as informações poderão ser acessadas remotamente e offline. Dessa forma, eles podem tomar decisões em tempo real, por exemplo, impedir o acesso a determinada área da obra, se for necessário. Caso haja situações irregularidades, também verifica a premência de treinamentos.

Portanto, em atribuição da necessidade do profissional de ter orientações em locais de perigo, o SEIF proporciona desenvolvimento de serventias com a utilização do totem, que é um sistema cyber-físico que funciona por meio da identificação do ID do trabalhador visando similarmente as suas capacitações, a sua localização, o posicionamento que o mesmo se encontra em uma zona de risco, exercendo um canal de comunicação entre a empresa e o trabalhador. A programação hardware incumbida pela identificação e localização do trabalhador na obra, procederia em expansões do sistema do mesmo modo, proporcionando amplificação de dados sobre a saúde dos trabalhadores, como batimentos cardíacos, temperatura, hidratação através de sensores. 
Revista Ceuma Perspectivas, Edição Especial. VII Congresso de Inovação, Tecnologia e Sustentabilidade Ceuma.

Vol. 34, nº2, 2019.

ISSN Eletrônico: 2525-5576.

Conforme o artigo publicado pelo SESI (2018), esta plataforma pode ser subdividida em 3 módulos divergentes que engloba as fases funcionais do sistema, que se define em:

- Módulo Regulatório: que se relaciona com as normas regulamentadoras, facilitando o processo de identificação de pontos críticos de proteção dos profissionais e redução do tempo gasto que possibilita identificar a criticidade gerando relatórios.

- Módulo Informação: onde se realiza o cadastro do trabalhador agregando as funções e habilidades dos profissionais, informando Atestado de Saúde Ocupacional e Equipamentos de Proteção Individual disponibilizados, reprimindo os riscos de multas e demandas trabalhistas na gestão.

- Módulo Comportamento: Por meio de sensores de monitoramento (hardwares e wearables) será disponibilizado mapeamento ativo dos trabalhadores quando submetidos a áreas de risco, propiciando $\mathrm{o}$ abrandamento de acidentes fatais.

Conforme a subdivisão das funções do SEIF averígua-se a versatilidade de desempenho que propicia ao responsável maior eficácia e rapidez no planejamento e monitoramento de operações de SST.

\section{CONCLUSÕES}

O SEIF concede uma melhoria no monitoramento e na gestão de segurança no trabalho inicialmente nas indústrias de construção civil, que potencializa comportamentos voltados para o bem-estar dos profissionais gerando um desempenho mais eficaz com o uso de tecnologia, minimizando esforços e otimizando a produção.

A implementação dessa proposta como inovação tecnológica em canteiros de obra agrega um alto valor na ICC, pois tem como princípios a economia, a sustentabilidade e a versatilidade, remetendo às concepções da indústria 4.0 apresentando um alto potencial de aplicabilidade não só para a Construção Civil, mas posteriormente em diferentes setores e indústrias. 
Revista Ceuma Perspectivas, Edição Especial. VII Congresso de Inovação, Tecnologia e Sustentabilidade Ceuma. Vol. 34, nº2, 2019. ISSN Eletrônico: 2525-5576.

\section{REFERÊNCIAS}

ACIDENTE DE TRABALHO NO BRASIL. Áreas SST, 2015. Disponível em: <https://areasst.com/acidentes-de-trabalho-no-brasil $>$. Acesso em: 12 maio 2019.

NOVAS TECNOLOGIAS GARANTEM A SAÚDE E A SEGURANÇA DO TRABALHADOR. Sempre Sesi Senai, 2018. Disponível em: $<$ http://www.sempresesisenai.com.br/preparando-para-o-futuro/centros-de-inovacaosesi-usam-novas-tecnologias-para-garantir-a-saude-e-a-seguranca-do-trabalhador/>. Acesso em: 15 maio 2019.

PLATAFORMA TECNOLÓGICA PARA PROMOÇÃO DE AMBIENTE DE TRABALHO E COMPORTAMENTOS SEGUROS NA INDÚSTRIA DA CONSTRUÇÃO CIVIL. CIS - Centro de Inovação SESI em Tecnologias para Saúde, 2018. Disponível em: <file://C:/Users/Dell/Downloads/projeto-seifpremio-cbic-de-inovacao-e-sustentabilidade.pdf>. Acesso em: 13 maio 2019. 